\title{
A Long-term Treatment with Silybin in Patients with Non-alcoholic Steatohepatitis Stimulates Catalase Activity in Human Endothelial Cells
}

\author{
ALESSANDRO FEDERICO ${ }^{1}$, VALERIA CONTI ${ }^{2}$, GIUSY RUSSOMANNO ${ }^{2}$, MARCELLO DALLIO $^{1}$, \\ MARIO MASARONE ${ }^{2}$, PAOLA STIUSO ${ }^{3}$, CONCETTA TUCCILLO ${ }^{1}$, MICHELE CARAGLIA $^{3}$, \\ VALENTINA MANZO ${ }^{2}$, MARCELLO PERSICO ${ }^{2}$, AMELIA FILIPPELLI $^{2}$ and CARMELINA LOGUERCIO ${ }^{1}$ \\ Departments of ${ }^{1}$ Clinical and Experimental Medicine and ${ }^{3}$ Biochemistry, \\ Biophysics and General Pathology, University of Campania "L. Vanvitelli", Naples, Italy; \\ ${ }^{2}$ Department of Medicine and Surgery, University of Salerno, Salerno, Italy
}

\begin{abstract}
Aim: To compare levels of oxidative stress markers in patients' sera with non-alcoholic steatohepatitis (NASH) treated for 12 months $\left(T_{12}\right)$ with silybin conjugated with phosphatidylcholine (Realsil $\left.{ }^{\circledR}\right)(R)$ or placebo $(P)$ and investigate oxidative stress responses in human endothelial cells conditioned with patients' sera. Patients and Methods: We recruited twenty-seven patients with histological NASH. We measured thiobarbituric acid reactive substances (TBARS), superoxide dismutase (SOD) and catalase (CAT) activities in human endothelial cells conditioned with patients' sera exposed or not to $\mathrm{H}_{2} \mathrm{O}_{2}$. Results: We found in decreased-TBARS patients' sera, at $T_{12}$, a decrease of alanine aminotransferase $(p=0.038)$, transforming growth factor-beta $(p=0.009)$ and procollagen $I(p=0.001)$. By dividing patients into two groups, increased $(P-I / R-I)$ and decreased TBARS (P-II/R-II) at $T_{12}$ compared to $T_{0}$, we found an increased $C A T$ activity in conditioned endothelial cells at $T 12$ in both groups ( $p=0.05$ and $p=0.001$, respectively). Conclusion: Realsil ${ }^{\circledR}$ may be effective against endothelial dysfunction by stimulating the cellular antioxidant defense.
\end{abstract}

Non-alcoholic fatty liver disease (NAFLD) is the most common chronic liver disease worldwide (1). NAFLD is

This article is freely accessible online.

Correspondence to: A. Federico, MD, Ph.D., Department of Clinical and Experimental Medicine, University of Campania "L. Vanvitelli", via Pansini 580131 Naples, Italy. Tel: +39 0815666723 , Fax: +39 0815666837, e-mail: alessandro.federico@unicampania.it

Key Words: Endothelial cells, non-alcoholic steatohepatitis, oxidative stress, silybin, thiobarbituric acid reactive substances. characterized by fat accumulation in the liver, leading to clinical conditions ranging from isolated steatosis to chronic inflammatory status represented by fibrosis, cirrhosis and hepatocellular carcinoma (2). In NAFLD patients, the amount of liver enzymes has been demonstrated to predict the incidence of cardiovascular diseases (CVDs), independently from the traditional risk factors, including $\mathrm{C}$-reactive protein and metabolic syndrome (MS). Moreover, the extent of liver damage has been correlated with early carotid atherosclerosis, suggesting that the injury to both vessels and liver share inflammatory mediators (3). For these reasons, NAFLD has been recently proposed as an early marker of atherosclerosis and endothelial dysfunction and, consequently, as an independent cardiovascular risk factor (4).

In insulin-resistant subjects, the presence of fatty liver has been correlated with an impairment of the systemic oxidant/antioxidant balance (indicated as oxidative stress) and endothelial dysfunction, independently from the presence of MS, adiposity and high levels of adipokines (4). It is well-known that oxidative stress is associated with endothelial dysfunction and $\operatorname{CVD}(5,6)$ and, in NAFLD patients, it triggers an inflammatory cascade and extracellular matrix deposition in the liver, favoring the development of non-alcoholic steatohepatitis (NASH). Even if the mechanisms linking NALFD to increased oxidative stress and endothelial dysfunction have not yet been fully clarified, impaired mitochondrial $\beta$-oxidation, high levels of oxidized low-density lipoprotein (LDL), dietary saturated fat and reduced antioxidant intake have been proposed as potential pathogenetic factors (7-10).

Administration of several natural polyphenols is now considered to be a valid therapeutic strategy due to the ability of these compounds in preserving endothelial function and contrasting CVD (11). Silybin, the major active constituent of silymarin, is a potent antioxidant agent (12). It attenuates the 
oxidative stress by inhibiting accumulation of oxidants, interferes with lipid peroxidation and increases expression and activity of the antioxidant enzymes (13). These effects have been reported during both in in vivo and in vitro experiments carried out in rat Kupffer cells, hepatocytes, HepG2 cells, isolated mitochondria from rat hepatocytes, as well as in rat models of ischemiareperfusion. Recently, it has been demonstrated that silybin also exerts a protective effect on endothelial cells and contributes to the improvement of endothelial dysfunction in the animal model of diabetes (14). Silybin is also administered as hepato-protective drug in patients with different forms of acute and chronic liver diseases, including NASH (15). The therapeutic response, mainly demonstrated by the improvement of liver damage, is reached in approximately $50 \%$ of the treated subjects. Moreover, we recently reported that this response was significantly correlated with the baseline serum oxidative stress, as well as with the variations of the serum oxidative and lipidomic profiles (16). In particular, we demonstrated that sera from patients with NASH induced lipid droplet accumulation in the cytoplasm of HepG2 cells, whereas a conditioning of the cells with sera of patients treated with silybin led to a reduction of intracellular fat accumulation. Of note, this effect was significantly correlated with baseline oxidative status and lipidomic variations induced by silybin. We identified two types of NASH patients differentiated by the presence of high or low systemic lipid peroxidation. Interestingly, these two groups of patients showed different therapeutic responses to silybin, evaluated by the following parameters: circulating oxidative stress, lipidomic profile and liver histology. In the present study, we evaluated whether sera isolated by NASH patients, treated with silybin conjugated with phosphatidylcholine $\left(\right.$ Realsil $\left.^{\circledR}\right)$ (R) for 12 months, modified the redox state and oxidative stress response of human endothelial cells (ECs) exposed, or not, to oxidative stress induction.

\section{Patients and Methods}

This interventional non-pharmacological prospective study is in compliance with ethical guidelines of the Declaration of Helsinki (1975) and has been approved by the Institutional Review Board at our Center (number 0018123/2015). All patients gave informed written consent.

Sera. Serum samples of twenty-seven out of 30 patients of a previous study with histological diagnosis of NASH (16) were used. Eleven serum samples from patients treated with placebo $(\mathrm{P})$ and 16 from patients treated with $\mathrm{R}$ for 12 months were collected at 0 $\left(\mathrm{T}_{0}\right)$ and after 12 months $\left(\mathrm{T}_{12}\right)$ and stored at $-80^{\circ} \mathrm{C}$ for later use.

Serum markers. Aspartate aminotransferase (AST), alanine aminotransferase (ALT), gamma-glutamyl transpeptidase (GGT), blood glucose and insulin were evaluated using enzyme-linked immunosorbent assay (ELISA) commercial kits (R\&D Systems, Minneapolis, MN, USA). Insulin-resistance was calculated by the homeostatic model assessment of insulin resistance (HOMA-IR test) (17).
Table I. Clinical and serological characteristics of enrolled patients (mean \pm standard deviation).

\begin{tabular}{lc}
\hline Number & 27 \\
Age (years) & $42 \pm 11$ \\
Gender $($ Male/Female) & $14 / 13$ \\
BMI $\left(\mathrm{kg} / \mathrm{m}^{2}\right)$ & $29.38 \pm 4.56$ \\
Obesity & 5 \\
Diabetes mellitus & 3 \\
Hypercholesterolemia & 3 \\
Hypertriglyceridemia & 2 \\
ALT $(\mathrm{IU} / \mathrm{l})$ & $59.65 \pm 30.18$ \\
AST $(\mathrm{IU} / \mathrm{l})$ & $32.24 \pm 9.85$ \\
GGT $(\mathrm{IU} / \mathrm{l})$ & $39.75 \pm 25.61$ \\
Glucose $(\mathrm{mg} / \mathrm{dl})$ & $85.13 \pm 38.21$ \\
Insulin $(\mu \mathrm{U} / \mathrm{ml})$ & $21.72 \pm 14.64$ \\
HOMA-IR & $4.05 \pm 2.07$ \\
\hline
\end{tabular}

BMI, Body mass index; ALT, alanine aminotransferase; AST, aspartate aminotransferase; GGT, gamma-glutamyltranspeptidase; HOMA-IR, the homeostatic model assessment of insulin resistance.

Cytokines and markers of liver fibrosis were assessed using ELISA kits: interleukin (IL)-10, transforming growth factor (TGF)$\beta$, tumor necrosis factor (TNF)- $\alpha$ and matrix metalloproteinases (MMP)-2 (R\&D Systems); hyaluronic acid (Echelon Biosciences Inc., Saltlake City, OK, USA); procollagen I and amino-terminal propeptide of type III procollagen (PIIINP) (Takara Bio Inc., Otsu, Shiga, Japan); tissue inhibitor of metalloproteinases (TIMP)-I (Invitrogen, Carlsbad, CA, USA); TIMP-II (Chemicon International, Millipore, Billerica, MA, USA).

Markers of oxidative stress. We evaluated the following markers of oxidative stress: (i) Thiobarbituric acid reactive substances (TBARS) (18).The assay was performed with $10 \mu \mathrm{l}$ of serum. The chromogen TBARS was quantified using a spectrophotometer at a wavelength of $532 \mathrm{~nm}$ with 1,1,3,3-tetramethoxyprophane as standard. The amount of TBARS was expressed as $n m o l / \mu \mathrm{g}$ of protein. Presented data are the mean $(\mathrm{M}) \pm$ standard deviation (SD) resulting from three independent experiments.

(ii) Superoxide dismutase (SOD) and catalase (CAT) activities were measured in both sera and cell lysates (Cayman Chemical, Ann Arbor, MI, USA) (19). For both assays, samples were previously diluted with buffer (1:10 for sera; 1:2 for cell lysates). One unit of SOD activity was defined as the amount of enzyme needed to exhibit $50 \%$ dismutation of superoxide radical. SOD assay measured all three types of SOD (Cu/Zn, Mn and FeSOD). One unit of CAT activity was defined as the amount of enzyme that led to the formation of $1.0 \mathrm{nmol}$ of formaldehyde per min at $25^{\circ} \mathrm{C}$. The values are reported as $\mathrm{U} / \mu \mathrm{g}$ of protein. The results derived from three independent experiments.

Cell culture and treatments. Human umbilical vein endothelial cells (HUVEC) (Clonetics, Walkersville, MD, USA) were used for in vitro experiments. ECs were cultured in EGM-2 Bullet Kit (Clonetics), containing vascular endothelial growth factor (VEGF), basic fibroblast growth factor (bFGF), insulin-like growth factor-1 (IGF-1), epidermal growth factor (EGF), hydrocortisone, heparin, gentamicin 
Federico et al: Silybin in Non-alcoholic Fatty Liver Disease

Table II. Biochemical parameters of patients at T0 and T12 of placebo $(P)$ or Realsil ${ }^{\circledR}(R)$ administration.

\begin{tabular}{|c|c|c|c|c|c|c|}
\hline & \multicolumn{2}{|c|}{$\mathrm{P}$ (10 patients) } & \multirow[b]{2}{*}{$p$-Value } & \multicolumn{2}{|c|}{$\mathrm{R}$ (17 patients) } & \multirow[b]{2}{*}{$p$-Value } \\
\hline & $\mathrm{T}_{0}$ & $\mathrm{~T}_{12}$ & & $\mathrm{~T}_{0}$ & $\mathrm{~T}_{12}$ & \\
\hline BMI $\left(\mathrm{kg} / \mathrm{m}^{2}\right)$ & $29.41 \pm 4.19$ & $29.50 \pm 4.47$ & 0.343 & $29.32 \pm 5.00$ & $29.22 \pm 5.06$ & 0.796 \\
\hline ALT (IU/1) & $56.25 \pm 32.26$ & $40.38 \pm 13.61$ & 0.110 & $66.21 \pm 32.91$ & $45.86 \pm 30.23$ & 0.038 \\
\hline AST (IU/l) & $33.38 \pm 11.86$ & $26.63 \pm 5.93$ & 0.095 & $31.93 \pm 8.54$ & $26.79 \pm 10.51$ & 0.090 \\
\hline GGT (IU/l) & $36.83 \pm 20.83$ & $39.17 \pm 14.57$ & 0.795 & $45.69 \pm 29.94$ & $39.21 \pm 20.77$ & 0.271 \\
\hline Glucose (mg/dl) & $95.13 \pm 48.23$ & $104.29 \pm 23.03$ & 0.548 & $81.73 \pm 39.89$ & $85.27 \pm 29.88$ & 0.184 \\
\hline Insulin $(\mu \mathrm{U} / \mathrm{ml})$ & $22.41 \pm 13.73$ & $9.53 \pm 6.39$ & 0.134 & $21.82 \pm 15.87$ & $16.83 \pm 7.22$ & 0.501 \\
\hline HOMA-IR & $4.25 \pm 2.27$ & $6.48 \pm 7.43$ & 0.961 & $3.94 \pm 1.93$ & $3.61 \pm 1.82$ & 0.433 \\
\hline IL-10 (pg/ml) & $37.15 \pm 23.95$ & $31.22 \pm 19.16$ & 0.194 & $32.76 \pm 19.87$ & $28.15 \pm 12.16$ & 0.324 \\
\hline MMP-2 (ng/ml) & $155.64 \pm 27.58$ & $184.18 \pm 62.44$ & 0.178 & $152.73 \pm 58.08$ & $167.44 \pm 83.78$ & 0.544 \\
\hline TGF- $\beta$ (ng/ml) & $20.83 \pm 13.41$ & $20.75 \pm 13.23$ & 0.987 & $20.82 \pm 9.50$ & $14.74 \pm 9.24$ & 0.009 \\
\hline TNF- $\alpha(\mathrm{pg} / \mathrm{ml})$ & $19.70 \pm 11.82$ & $23.39 \pm 9.55$ & 0.400 & $24.66 \pm 14.48$ & $28.51 \pm 13.09$ & 0.373 \\
\hline TIMPI (ng/ml) & $304.36 \pm 126.40$ & $296.18 \pm 78.31$ & 0.805 & $316.67 \pm 75.73$ & $316.69 \pm 90.62$ & 0.997 \\
\hline TIMPII (ng/ml) & $47.73 \pm 22.94$ & $67.36 \pm 51.48$ & 0.196 & $65.13 \pm 45.15$ & $54.06 \pm 34.47$ & 0.493 \\
\hline Hyaluronic acid (ng/ml) & $277.36 \pm 218.71$ & $291.55 \pm 246.99$ & 0.722 & $234.27 \pm 120.39$ & $244.56 \pm 147.46$ & 0.684 \\
\hline PIIINP (ng/ml) & $108.28 \pm 47.01$ & $109.54 \pm 53.87$ & 0.665 & $128.04 \pm 44.57$ & $116.61 \pm 33.76$ & 0.736 \\
\hline Procollagen I (ng/ml) & $308.45 \pm 60.08$ & $293.18 \pm 80.11$ & 0.538 & $308.20 \pm 88.61$ & $244.44 \pm 58.40$ & 0.001 \\
\hline
\end{tabular}

$\mathrm{T}_{0}$, Baseline; $\mathrm{T}_{12}$, after 12 months; BMI, body mass index; ALT, alanine aminotransferase; AST, aspartate aminotransferase; GGT, gamma-glutamyl transpeptidase; HOMA-IR, the homeostatic model assessment of insulin resistance; IL-10, interleukin-10; MMP-2, matrix metalloproteinase-2; TGF- $\beta$, transforming growth factor-beta; TNF- $\alpha$, tumor necrosis factor-alpha; TIMPI/II, tissue inhibitor of metalloproteinase-I/II; PIIINP, amino terminal propeptide of type III procollagen.

sulfate amphotericin, ascorbic acid and $2 \%$ fetal bovine serum (FBS). The cells were subcultured by trypsinization, seeded on cell culture dishes and grown at an atmosphere of $5 \% \mathrm{CO}_{2}$ at $37^{\circ} \mathrm{C}$.

The cells were cultured in medium supplemented with patients' sera $(10 \%)$ (P-ECs or R-ECs, corresponding to patients treated with $\mathrm{P}$ or R, respectively) or FBS (10\%) as a control. Some cells were exposed to oxidative stress with hydrogen peroxide $\left(\mathrm{H}_{2} \mathrm{O}_{2}\right)$, similarly to what has been described in previous studies $(5,20)$. Briefly, the cells were seeded and cultured for $48 \mathrm{~h}$ in medium supplemented as previously described. Later, the culture medium was aspirated and ECs were exposed to $500 \mu \mathrm{M} \mathrm{H}_{2} \mathrm{O}_{2}$; four hours after $\mathrm{H}_{2} \mathrm{O}_{2}$ exposure, growth medium was replaced with fresh medium containing FBS and cells were maintained in culture for another 48 -h period.

All experiments were performed at a population doubling level (PDL) of 8 to 12 .

Statistical analysis. Continuous variables are expressed as $\mathrm{M} \pm \mathrm{SD}$ and compared with the use of Student's $t$-test (normally distributed) or as median \pm interquartile range value and compared with the use of Mann-Whitney $U$-test (not normally distributed). Normality of data distribution was evaluated using Kolmogorov-Smirnov test. All data were analyzed by SPSS version 15.0 (SPSS, Inc., Chicago, IL, USA). Statistical significance was accepted at $p<0.05$ in a twotailed test. Alessandro Federico and Valeria Conti analyzed the data.

\section{Results}

Effects of placebo $(P)$ and $R$ on serum markers of oxidative stress. Clinical and serological characteristics of the enrolled patients are reported in Table I.
Table II reports biochemical parameters of the enrolled patients at baseline $\left(\mathrm{T}_{0}\right)$ and after 12 months $\left(\mathrm{T}_{12}\right)$ of $\mathrm{P}$ or $\mathrm{R}$ administration. After 12 months, no differences in $\mathrm{P}$ group were found; conversely, ALT $(p=0.038)$, TGF- $\beta$ $(p=0.009)$ and procollagen I $(p=0.001)$ values significantly decreased at $\mathrm{T}_{12}$ after $\mathrm{R}$ treatment. Figure 1 (panels A, B and $C$ ) summarizes the serum levels of TBARS, SOD and CAT activities found in the sera at $\mathrm{T}_{0}$ and $\mathrm{T}_{12}$ of $\mathrm{P}$ or $\mathrm{R}$ administration. As shown, no significant changes were found.

As reported in a previous study (16), we identified patients showing very low or very high levels of TBARS at baseline when compared to those of healthy controls. Thus, we divided patients (both $\mathrm{P}$ and $\mathrm{R}$ ) into two groups on the basis of the trend of TBARS serum levels between baseline and after 12 months of treatment with $\mathrm{P}$ or $\mathrm{R}$, in order to evaluate any potential differences of antioxidant response between these two groups. Seven patients who showed a significant increase of TBARS values at $\mathrm{T}_{12}$ compared to $\mathrm{T}_{0}$ $(p<0.01)$ were included in the first group of patients treated with R (R-I), whereas 10 patients who showed a decrease of TBARS at $\mathrm{T}_{12}\left(p<0.01 v s . \mathrm{T}_{0}\right.$ values $)$ were included in the second group (R-II). Of note, in the $\mathrm{P}$ group, we did not find any statistically significant variation in the TBARS levels after 12 months (Figure 2, panel A).

Taking into consideration the first division in two groups in relation to TBARS trend, we analyzed two additional 
markers of oxidative stress (SOD and CAT) activities at baseline and after 12 months of treatment with $\mathrm{P}$ or R.

No significant differences in SOD activity between $\mathrm{T}_{0}$ and $\mathrm{T}_{12}$, both in $\mathrm{P}$ and $\mathrm{R}$ groups, were found (Figure 2, panel B). Conversely, CAT activity exclusively decreased in the R-I group $(p<0.01)$ after 12 months of $\mathrm{R}$ administration (Figure 2, panel C).

Biochemical variables of the study population, divided into two groups (I and II) for each considered treatment ( $P$ and R), are listed in Tables III and IV. In patients treated with P, both P-I and P-II, no differences were found before and after treatment (Table III). By contrast, a significant reduction of procollagen $\mathrm{I}$ after 12 months of $\mathrm{R}$ administration was found in both R-I $(p=0.018)$ and R-II $(p=0.030)$ groups. Interestingly, in $\mathrm{R}-\mathrm{II}$ group, we also recorded a significant reduction of $\operatorname{ALT}(p=0.041)$ and TGF$\beta(p=0.015)$ after 12 months of $\mathrm{R}$ administration (Table IV).

Effects of sera on ECs. We used HUVEC in cultures conditioned with medium supplemented with NASH patients' sera $(10 \%)$ in order to evaluate if the sera were able to determine an antioxidant response in ECs with or without an oxidative $\mathrm{H}_{2} \mathrm{O}_{2}$ stimulus. We performed this experiment in order to create a microenvironment similar to the oxidative state present in serum of patients. As shown in Figure 3 (panel A), no difference in SOD activity between $T_{0}$ and $T_{12}$ in cell cultures supplemented with patients' sera treated with $\mathrm{P}$, both PI and PII (PI/II-ECs), was found. Treatment with $\mathrm{H}_{2} \mathrm{O}_{2}$ did not induce any change in SOD activity between $\mathrm{T}_{0}$ and $\mathrm{T}_{12}$ in both PI-ECs and PII-ECs. In cells cultured in medium supplemented with patients' sera (10\%), treated with R (RI/IIECs), we recorded a drastic reduction in SOD activity at $\mathrm{T}_{12}$ $(p=0.001)$ after induction of oxidative stress in RI-ECs, whereas no difference was found in RII-ECs.

No difference in CAT activity between $\mathrm{T}_{0}$ and $\mathrm{T}_{12}$, in both PI-ECs and PII-ECs, was found; moreover, treatment with $\mathrm{H}_{2} \mathrm{O}_{2}$ did not induce any change between $\mathrm{T}_{0}$ and $\mathrm{T}_{12}$. Conversely, we recorded a significant increase in CAT activity, with and without induction of oxidative stress, between $\mathrm{T}_{0}$ and $\mathrm{T}_{12}$ in both RI-ECs and RII-ECs $(p=0.05$ and $p=0.001$; Figure 3 , panel $\mathrm{B}$ ).

\section{Discussion}

NAFLD is associated with MS, which is characterized by the coexistence of atherogenic dyslipidemia, elevated blood pressure, elevated glucose/insulin resistance, prothrombotic state and a low-grade inflammation $(21,22)$.

These conditions are cardiovascular risk factors and patients affected by this syndrome have an elevated probability to develop a cardiovascular pathology that, in turn, represents one of the main causes of death in this population (23).
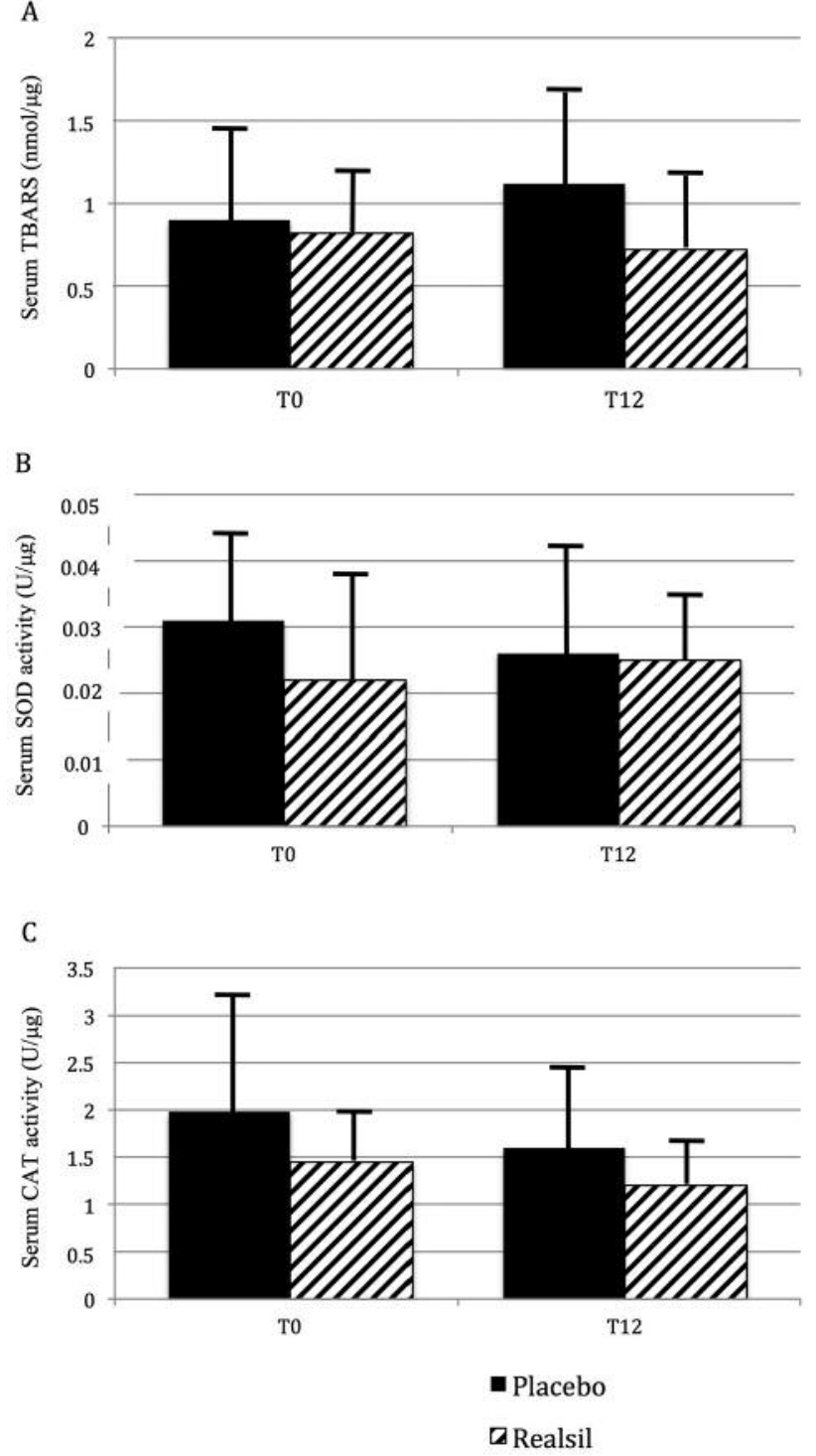

Figure 1. Serum levels of thiobarbituric acid reactive substances

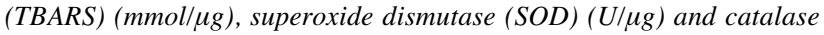
(CAT) $(U / \mu g)$ activities at baseline $\left(T_{0}\right)$ and after 12 months $\left(T_{12}\right)$ of placebo or Realsil ${ }^{\circledR}$ administration.

In recent years, the role of NAFLD in inducing CVD has been investigated; moreover, it may be considered as an independent risk factor for cardiovascular pathologies $(2,24)$.

Among the several processes involved in the mechanism linking NAFLD and CVD, oxidative stress and endothelial dysfunction (in turn, strongly inter-correlated) appear to play an important pathogenic role (25). Recent studies have showed that NAFLD is associated to endothelial dysfunction, that is characterized by oxidative stress accumulation and considered as a surrogate marker of CVD (26). 
.

A

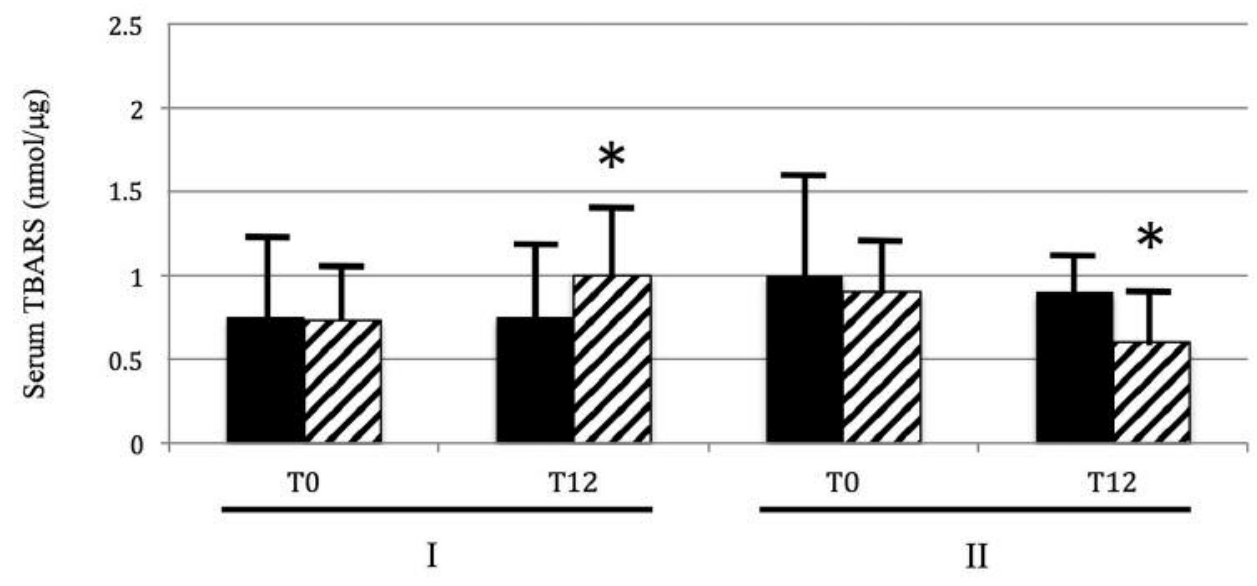

B

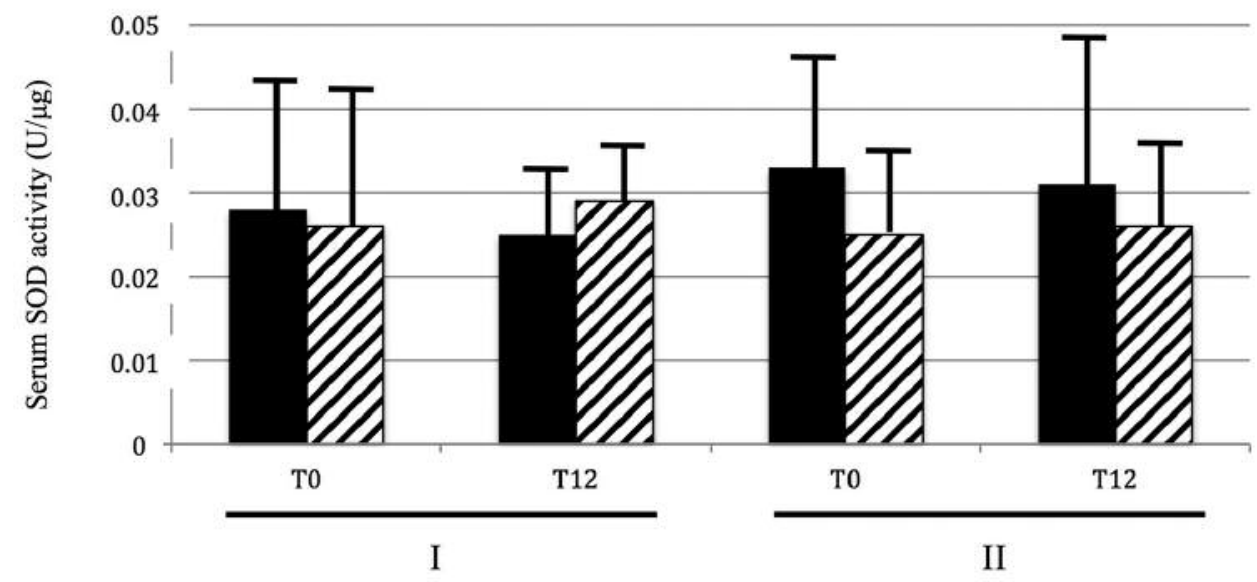

C

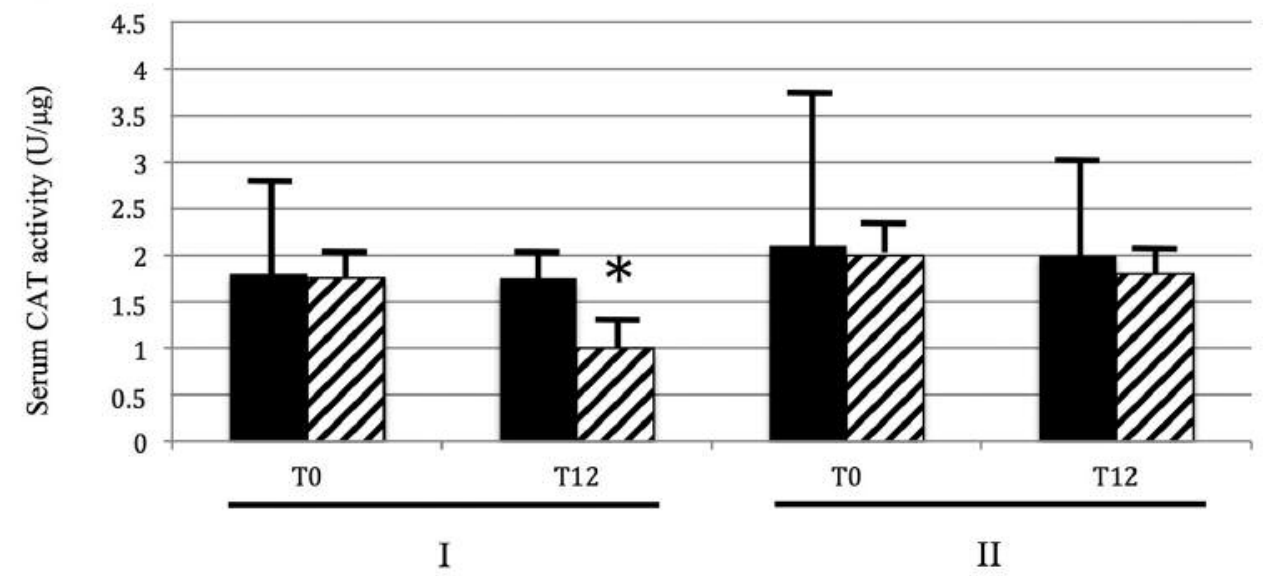

- Placebo

ZRealsil

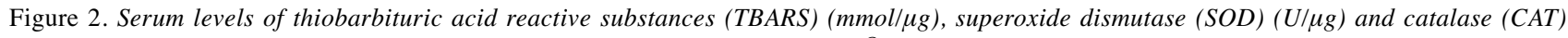
$(U / \mu g)$ activities at baseline $\left(T_{0}\right)$ and after 12 months $\left(T_{12}\right)$ of placebo or Realsil ${ }^{\circledR}$ administration in stratified patients into two groups on the basis of the trend of TBARS serum levels. A: ${ }^{*} p<0.01 v s . T_{0} ; C: * p<0.01 \mathrm{vs} . T_{0}$. 
in vivo $31: 609-618(2017)$

Table III. Biochemical variables of patients stratified into two groups (I and II) for placebo (P) treatment.

\begin{tabular}{|c|c|c|c|c|c|c|}
\hline & \multicolumn{2}{|c|}{ P-I (5 patients) } & \multirow[b]{2}{*}{$p$-Value } & \multicolumn{2}{|c|}{ P-II (5 patients) } & \multirow[b]{2}{*}{$p$-Value } \\
\hline & $\mathrm{T}_{0}$ & $\mathrm{~T}_{12}$ & & $\mathrm{~T}_{0}$ & $\mathrm{~T}_{12}$ & \\
\hline BMI $\left(\mathrm{kg} / \mathrm{m}^{2}\right)$ & $29.59 \pm 5.10$ & $29.61 \pm 5.37$ & 0.404 & $28.93 \pm 3.92$ & $28.84 \pm 3.86$ & 0.811 \\
\hline ALT (IU/l) & $70.79 \pm 33.70$ & $49.00 \pm 28.39$ & 0.271 & $48.25 \pm 25.42$ & $34.88 \pm 16.19$ & 0.368 \\
\hline AST (IU/l) & $34.21 \pm 9.85$ & $29.00 \pm 10.00$ & 0.251 & $29.38 \pm 8.96$ & $22.75 \pm 5.12$ & 0.245 \\
\hline GGT (IU/l) & $44.46 \pm 30.93$ & $40.50 \pm 20.93$ & 0.871 & $39.50 \pm 18.25$ & $32.43 \pm 15.71$ & 0.751 \\
\hline Glucose (mg/dl) & $76.00 \pm 40.22$ & $94.75 \pm 15.28$ & 0.777 & $125.00 \pm 49.67$ & $117.00 \pm 28.58$ & 0.503 \\
\hline Insulin $(\mu \mathrm{U} / \mathrm{ml})$ & $21.85 \pm 16.58$ & $13.11 \pm 8.18$ & 0.136 & $22.45 \pm 11.39$ & $15.18 \pm 6.76$ & 0.212 \\
\hline HOMA-IR & $3.63 \pm 1.73$ & $3.35 \pm 1.91$ & 0.356 & $4.88 \pm 2.40$ & $7.06 \pm 7.04$ & 0.110 \\
\hline IL-10 (pg/ml) & $31.41 \pm 20.17$ & $27.97 \pm 14.14$ & 0.619 & $38.36 \pm 22.93$ & $31.20 \pm 16.74$ & 0.251 \\
\hline MMP-2 (ng/ml) & $152.71 \pm 58.20$ & $174.67 \pm 91.82$ & 0.211 & $155.42 \pm 31.32$ & $173.75 \pm 50.52$ & 0.547 \\
\hline TGF- $\beta(\mathrm{ng} / \mathrm{ml})$ & $23.35 \pm 12.75$ & $17.40 \pm 11.64$ & 0.606 & $17.88 \pm 8.28$ & $16.92 \pm 11.16$ & 0.621 \\
\hline TNF- $\alpha(\mathrm{pg} / \mathrm{ml})$ & $18.49 \pm 13.96$ & $26.77 \pm 12.90$ & 0.179 & $27.32 \pm 11.49$ & $25.99 \pm 10.94$ & 0.937 \\
\hline TIMPI (ng/ml) & $340.36 \pm 113.82$ & $315.00 \pm 83.00$ & 0.628 & $277.75 \pm 65.57$ & $300.00 \pm 90.10$ & 0.719 \\
\hline TIMPII (ng/ml) & $46.86 \pm 22.69$ & $57.80 \pm 42.76$ & 0.300 & $70.50 \pm 48.07$ & $61.58 \pm 42.41$ & 0.440 \\
\hline Hyaluronic acid (ng/ml) & $179.07 \pm 89.93$ & $174.20 \pm 101.40$ & 0.839 & $338.17 \pm 196.41$ & $375.58 \pm 220.80$ & 0.799 \\
\hline PIIINP (ng/ml) & $115.71 \pm 44.36$ & $99.09 \pm 45.71$ & 0.687 & $125.05 \pm 48.84$ & $127.94 \pm 35.40$ & 0.957 \\
\hline Procollagen I (ng/ml) & $303.00 \pm 75.58$ & $270.60 \pm 82.47$ & 0.964 & $314.50 \pm 80.29$ & $256.42 \pm 55.82$ & 0.201 \\
\hline
\end{tabular}

$\mathrm{T}_{0}$, Baseline; $\mathrm{T}_{12}$, after 12 months; BMI, body mass index; ALT, alanine aminotransferase; AST, aspartate aminotransferase; GGT, gamma-glutamyl transpeptidase; HOMA-IR, the homeostatic model assessment of insulin resistance; IL-10, interleukin-10; MMP-2, matrix metalloproteinase-2; TGF$\beta$, transforming growth factor-beta; TNF- $\alpha$, tumor necrosis factor-alpha; TIMPI/II, tissue inhibitor of metalloproteinase-I/II; PIIINP, amino terminal propeptide of type III procollagen.

Table IV. Biochemical variables of patients stratified into two groups (I and II) for Realsil ${ }^{\circledR}(R)$ treatment.

\begin{tabular}{|c|c|c|c|c|c|c|}
\hline & \multicolumn{2}{|c|}{ R-I (7 patients) } & \multirow[b]{2}{*}{$p$-Value } & \multicolumn{2}{|c|}{ R-II (10 patients) } & \multirow[b]{2}{*}{$p$-Value } \\
\hline & $\mathrm{T}_{0}$ & $\mathrm{~T}_{12}$ & & $\mathrm{~T}_{0}$ & $\mathrm{~T}_{12}$ & \\
\hline BMI $\left(\mathrm{kg} / \mathrm{m}^{2}\right)$ & $30.05 \pm 6.00$ & $29.96 \pm 6.19$ & 0.850 & $27.99 \pm 2.41$ & $27.90 \pm 1.80$ & 0.879 \\
\hline ALT (IU/l) & $80.33 \pm 32.05$ & $55.22 \pm 33.65$ & 0.102 & $40.80 \pm 14.48$ & $29.00 \pm 12.35$ & 0.041 \\
\hline AST (IU/l) & $33.56 \pm 7.30$ & $29.56 \pm 11.81$ & 0.258 & $29.00 \pm 10.68$ & $21.80 \pm 5.63$ & 0.266 \\
\hline GGT (IU/1) & $48.25 \pm 36.03$ & $40.67 \pm 24.15$ & 0.501 & $41.60 \pm 19.58$ & $36.60 \pm 14.91$ & 0.282 \\
\hline Glucose (mg/dl) & $79.17 \pm 29.54$ & $82.43 \pm 37.48$ & 0.311 & $84.80 \pm 53.53$ & $90.25 \pm 10.69$ & 0.385 \\
\hline Insulin $(\mu \mathrm{U} / \mathrm{ml})$ & $25.68 \pm 19.90$ & $16.32 \pm 8.45$ & 0.485 & $16.03 \pm 4.59$ & $18.35 \pm 1.20$ & 0.877 \\
\hline HOMA-IR & $3.23 \pm 0.89$ & $3.60 \pm 2.15$ & 0.404 & $5.00 \pm 2.72$ & $3.66 \pm 0.62$ & 0.815 \\
\hline IL-10 (pg/ml) & $34.84 \pm 21.80$ & $30.56 \pm 10.01$ & 0.605 & $30.39 \pm 18.82$ & $25.06 \pm 14.70$ & 0.296 \\
\hline MMP-2 (ng/ml) & $154.50 \pm 74.01$ & $169.56 \pm 109.97$ & 0.901 & $150.71 \pm 38.34$ & $164.71 \pm 37.55$ & 0.366 \\
\hline TGF- $\beta(\mathrm{ng} / \mathrm{ml})$ & $24.85 \pm 9.99$ & $17.00 \pm 10.58$ & 0.090 & $16.21 \pm 6.90$ & $11.83 \pm 6.82$ & 0.015 \\
\hline $\mathrm{TNF}-\alpha(\mathrm{pg} / \mathrm{ml})$ & $22.50 \pm 15.88$ & $31.74 \pm 13.97$ & 0.092 & $27.13 \pm 13.49$ & $24.35 \pm 11.48$ & 0.608 \\
\hline TIMPI (ng/ml) & $340.38 \pm 82.87$ & $316.11 \pm 74.40$ & 0.357 & $289.57 \pm 61.36$ & $317.43 \pm 114.67$ & 0.385 \\
\hline TIMPII (ng/ml) & $49.25 \pm 24.73$ & $56.89 \pm 41.34$ & 0.425 & $83.29 \pm 57.64$ & $50.43 \pm 25.79$ & 0.099 \\
\hline Hyaluronic acid (ng/ml) & $169.00 \pm 79.22$ & $155.67 \pm 51.47$ & 0.349 & $308.86 \pm 119.68$ & $358.86 \pm 154.06$ & 0.505 \\
\hline PIIINP (ng/ml) & $117.43 \pm 47.07$ & $99.81 \pm 29.50$ & 0.871 & $140.42 \pm 42.05$ & $130.04 \pm 33.46$ & 0.349 \\
\hline Procollagen I (ng/ml) & $293.00 \pm 83.74$ & $241.44 \pm 42.09$ & 0.018 & $325.57 \pm 97.36$ & $248.29 \pm 39.56$ & 0.030 \\
\hline
\end{tabular}

$\mathrm{T}_{0}$, Baseline; $\mathrm{T}_{12}$, after 12 months; BMI, body mass index; ALT, alanine aminotransferase; AST, aspartate aminotransferase; GGT, gamma-glutamyl transpeptidase; HOMA-IR, the homeostatic model assessment of insulin resistance; IL-10, interleukin-10; MMP-2, matrix metalloproteinase-2; TGF$\beta$, transforming growth factor-beta; TNF- $\alpha$, tumor necrosis factor-alpha; TIMPI/II, tissue inhibitor of metalloproteinase-I/II; PIIINP, amino terminal propeptide of type III procollagen.

Recently, the protective role of silybin on endothelial cells has been demonstrated. Silybin has both antioxidant and antiinflammatory properties $(13,27-31)$, as well as anti-fibrotic ones (32). However, even if the effectiveness of this natural compound against liver damage has been largely documented, its therapeutic potential in attenuating cardiovascular risk 


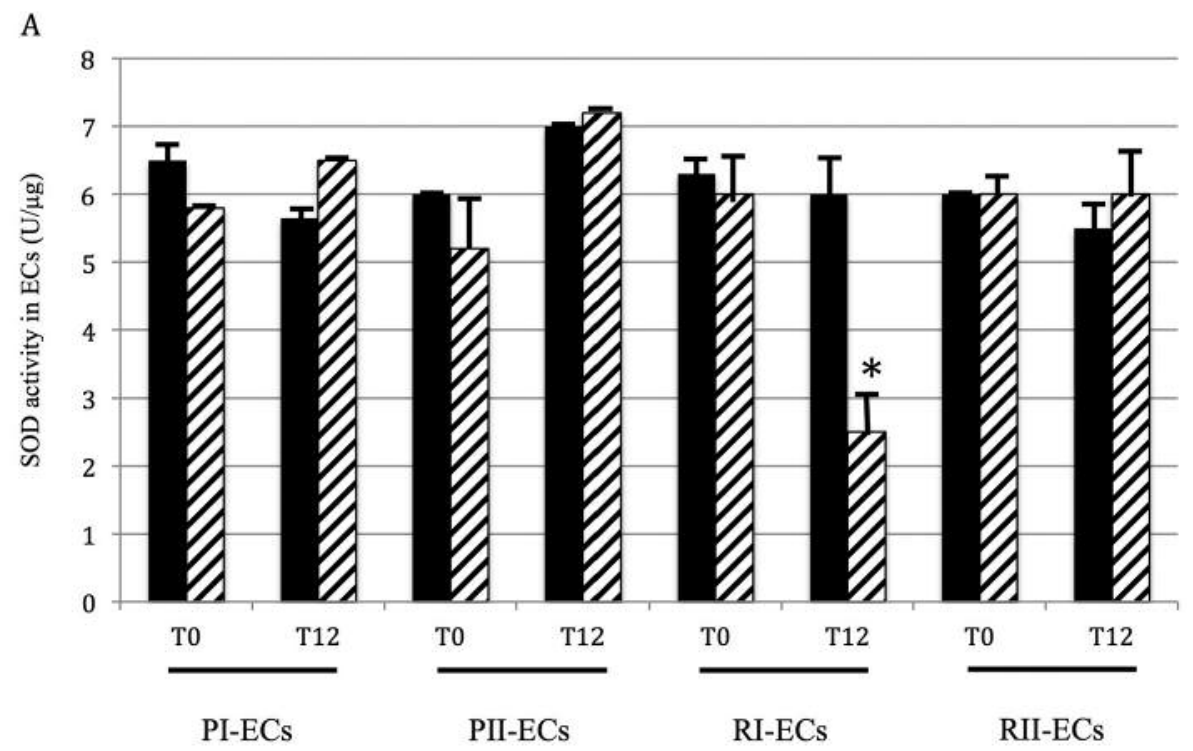

B

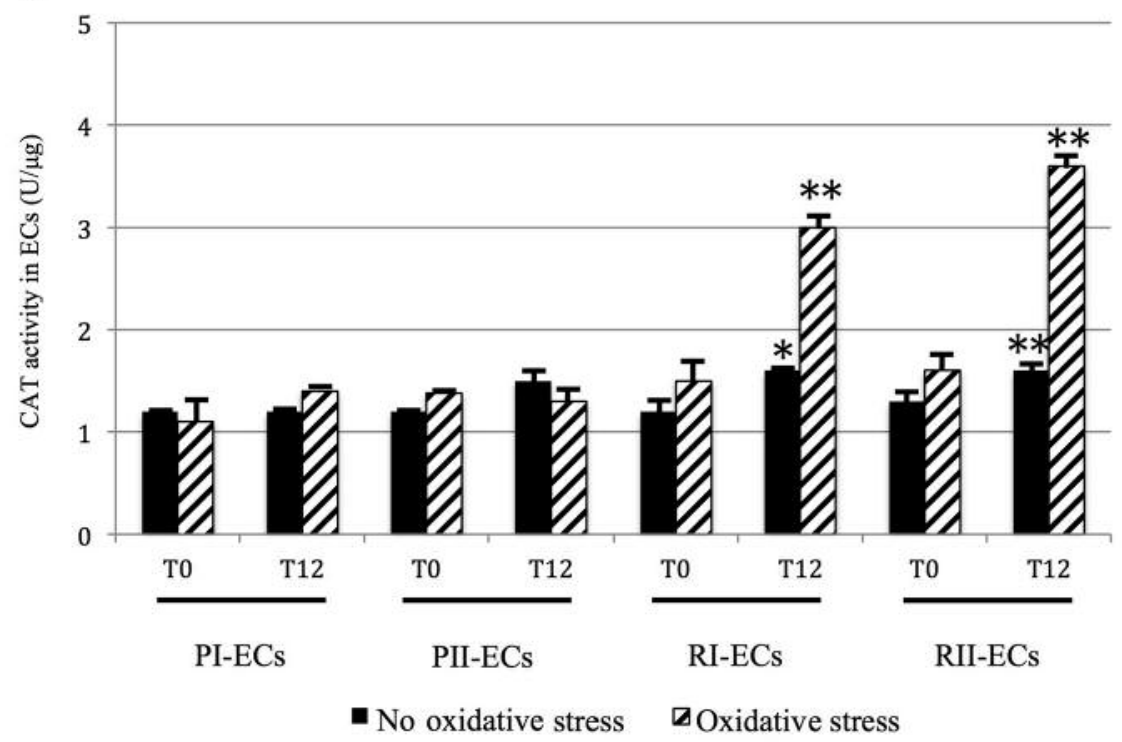

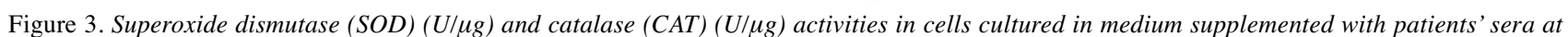
baseline $\left(T_{0}\right)$ and after 12 months $\left(T_{12}\right)$ of placebo $(P)$ or Realsil ${ }^{\circledR}(R)$ administration, stratified into two groups on the basis of the trend of TBARS serum levels, with or without oxidative stress induction. $A:{ }^{*} p=0.001 \mathrm{vs} . T_{0} ; B:{ }^{*} p=0.05 \mathrm{vs} . T_{0} ; * * p=0.001 \mathrm{vs} . T_{0}$.

factors, including endothelial dysfunction, has yet to be determined. For these reasons, we used $\mathrm{R}$ in order to try and modify the serum redox state of NASH patients and to evaluate if these modifications were able to induce an antioxidant response in ECs' cultures conditioned with serum of these patients.

In order to evaluate the redox state of NASH patients, we assessed the following markers of oxidative stress: TBARS, SOD and CAT activities before $\left(\mathrm{T}_{0}\right)$ and after $\left(\mathrm{T}_{12}\right)$ treatment with P or R.
As in a previous study (16), we identified an opposite trend in TBARS levels among the patients treated with $\mathrm{R}$. Thus, we divided the patients into two groups on the basis of the incremental or decremental trend of TBARS levels, $\mathrm{P} / \mathrm{R}-\mathrm{I}$ and P/R-II, respectively. On the basis of this subdivision, we found, at the end of 12 months of $\mathrm{R}$ administration, a decrease of CAT activity in patients showing an increase of TBARS, whereas no change in patients showing a decrease of TBARS was found (R-I group). 
Moreover, RI and RII groups showed a decrease of procollagen I, a well-known marker of fibrosis, after 12 months of treatment. Finally, in R-II patients, who showed a decrease of TBARS at $\mathrm{T}_{12}$, a reduction of ALT and TGF- $\beta$ was also found. The reduction of TGF- $\beta$ levels may contribute to limit fibrotic tissue deposition. Indeed, TGF- $\beta$ represents one of the main cytokines able to sustain collagen synthesis and, therefore, fibrosis through transformation of hepatic stellate cells in myofibroblasts (33). On the contrary, in our study, tissue inhibitor of metalloproteinase (TIMP) I/II, matrix metalloproteinase (MMP)-2 and amino terminal propeptide of type III procollagen (PIIINP), other known serum parameters able to predict liver fibrosis, did not show statistically significant changes after $\mathrm{R}$ treatment. It is possible that this may be attributed to the limited sample size, as well as the limited time of observation (12 months).

In summary, in R-II patients' sera, we observed a decrease of lipid peroxidation after 12 months of treatment, concurrently with a decrease of ALT and two important profibrotic factors: TGF- $\beta$ and procollagen I.

As mentioned above, ALT has been recently shown to be associated with endothelial dysfunction and, therefore, proposed as a predictive factor for coronary events (3). Since the endothelial dysfunction is recognized as an early marker of NAFLD and taking into consideration the antioxidant property of silybin, we tested the hypothesis that $\mathrm{R}$ could be useful in contrasting endothelial dysfunction. Therefore, we adopted the in vitro-in vivo technique already used in our previous studies by which we demonstrated the capacity of sera isolated either from athletes $(5,20)$ or NASH patients treated with $\mathrm{R}$ (16) to stimulate the oxidative stress response in endothelial cells and HepG2 cells, respectively. Thus, we conditioned human endothelial cells with sera isolated from patients before and after $\mathrm{P}$ or $\mathrm{R}$ administration.

We performed this experiment in order to create a cellular microenvironment similar to the oxidative state present in the serum of patients. Obviously, this experiment does not reflect the intracellular redox state in vivo; however, our aim was to evaluate the response of ECs' cultures to the serum redox state modifications that treatment with $\mathrm{P}$ or $\mathrm{R}$ could cause.

Cells conditioned with sera from R-I patients showed an increase of CAT activity after $\mathrm{R}$ treatment $\left(\mathrm{T}_{12}\right)$, whereas cells conditioned with R-II sera showed a higher increase of CAT activity after $\mathrm{R}$ treatment. Importantly, this finding was observed both in the presence and absence of $\mathrm{H}_{2} \mathrm{O}_{2}$. No differences in the cells conditioned with sera isolated from patients treated with $\mathrm{P}$ were found.

We hypothesized that the increased levels of TBARS, reached in R-I patients sera at $T_{12}$, may have stimulated CAT activity in human ECs. The decrease of CAT serum activity and the increase of CAT activity in ECs conditioned with R-I patient's sera could be due to the possibility that CAT activity decreases since its function is partially substituted with the antioxidant effect of R. On the contrary, in ECs conditioned with RII patient's sera at $\mathrm{T}_{12}$, increased CAT activity may be due to the direct effect of $\mathrm{R}$, which could modify serum micromolecular composition, thus leading to the production of substances that increase CAT activity in ECs, through the interaction with specific receptors, independently of serum levels of TBARS at $\mathrm{T}_{12}$. Particularly, the higher increase of cellular CAT activity, induced by $\mathrm{R}$, in RII-ECs may be associated to a reduction of liver cytonecrosis indices. Further studies are needed in order to identify mediators responsible for the observed phenomenon.

The role of CAT in hepatic fibrosis has been recently investigated. Dong et al. demonstrated that overexpression of CAT leads to a decrease in the secretion of collagen type 1 in hepatic stellate cells (34). Moreover, Hernández-Ortega et al. showed that quercetin, a potent activator of SOD and CAT, improves hepatic fibrosis by reducing the expression of pro-fibrogenic molecules, including collagen $1 \alpha$, connective tissue growth factor and TGF- $\beta$ (35).

In this way, the trend of TBARS could be considered as a predictive marker of antioxidant response to $\mathrm{R}$ treatment; further studies, however, should be addressed in order to investigate whether the amount of TBARS in R-II patients could be reduced as a consequence of adaptive response in the endothelium of such patients.

In conclusion, the link between NAFLD and endothelial dysfunction, that is associated with cardiovascular pathologies, is a current research topic. The role played by oxidative stress in endothelial dysfunction is now recognized; however, further efforts should be addressed to clarify both its involvement in the onset and progression of NAFLD and the relationship between NAFLD and CVD.

The use of R, which has anti-inflammatory, antioxidant and anti-fibrotic properties, determines a slowdown of liver damage and could contribute, at least in part, to reduction of the incidence of CVD in patients with NAFLD, through the perturbation of redox state homeostasis.

Patients with higher levels of TBARS at $\mathrm{T}_{0}$ demonstrated an improvement of fibrosis, pro-inflammatory and cytonecrosis biomarkers after 12 months of $\mathrm{R}$ administration. In this way, the trend of TBARS could be considered as a predictive marker of antioxidant response to $\mathrm{R}$ treatment. We hypothesized that these effects may be triggered by treatment with $\mathrm{R}$, through a modulation of the response to oxidative stress both at the cellular and serum level. This may contribute to the improvement of the endothelial dysfunction in patients with MS, by intervening on the vicious circle that links MS and NASH to CVD. 


\section{Acknowledgements}

The Authors would like to thank Dr. Maddalena Farina (Second cycle degree in Linguistics and Translation for Special Purposes) for her assistance in English.

\section{References}

1 Younossi ZM, Koenig AB, Abdelatif D, Fazel Y, Henry L and Wymer M: Global epidemiology of non-alcoholic fatty liver disease-meta-analytc assessment of prevalence, incidence and outcomes. Hepatology 64: 73-84, 2016.

2 Buzzetti E, Pinzani $M$ and Tsochatzis EA: The multiple-hit pathogenesis of non-alcoholic fatty liver disease (NAFLD). Metabolism 65: 1038-1048, 2016.

3 Targher G, Bertolini L, Padovani R, Rodella S, Zoppini G, Zenari L, Cigolini M, Falezza G and Arcaro G: Relations between carotid artery wall thickness and liver histology in subjects with non-alcoholic fatty liver disease. Diabetes Care 29: 1325-1330, 2006.

4 Musso G, Gambino R, Bo S, Uberti B, Biroli G, Pagano G and Cassader M: Should nonalcoholic fatty liver disease be included in the definition of metabolic syndrome? A cross-sectional comparison with adult treatment panel III criteria in nonobesenondiabetic subjects. Diabetes Care 31: 562-568, 2008.

5 Conti V, Corbi G, Russomanno G, Simeon V, Ferrara N, Filippelli W, Limongelli F, Canonico R, Grasso C, Stiuso P, Dicitore A and Filippelli A: Oxidative stress effects on endothelial cells treated with different athletes' sera. Med Sci Sports Exerc 44: 39-49, 2012.

6 Reriani MK, Lerman LO and Lerman A: Endothelial function as a functional expression of cardiovascular risk factors. Biomark Med 4: 351-360, 2010.

7 Musso G, Gambino R, Durazzo M, Biroli G, Carello M, Fagà E, Pacini G, De Michieli F, Rabbione L, Premoli A, Cassader M and Pagano G: Adipokines in NASH: Postprandial lipid metabolism as a link between adiponectin and liver disease. Hepatology 42: 1175-1183, 2005.

8 Musso G, Cassader M, Gambino R, Durazzo M and Pagano G: Association between postprandial LDL conjugated dienes and the severity of liver fibrosis in NASH. Hepatology 43: 11691170, 2006

9 Musso G, Gambino R, De Michieli F, Cassader M, Rizzetto M, Durazzo M, Fagà E, Silli B and Pagano G: Dietary habits and their relations to insulin resistance and postprandial lipemia in non-alcoholic steatohepatitis. Hepatology 37: 909-916, 2003.

10 Musso G, Gambino R, De Michieli F, Biroli G, Premoli A, Pagano G, Bo S, Durazzo M and Cassader M: Nitrosative stress predicts the presence and severity of nonalcoholic fatty liver at different stages of the development of insulin resistance and metabolic syndrome: possible role of vitamin A intake. Am J Clin Nutr 86: 661-671, 2007.

11 Manach C, Mazur A and Scalbert A: Polyphenols and prevention of cardiovascular diseases. Curr Opin Lipidol 16: 77-84, 2005.

12 Loguercio C and Festi D: Silybin and the liver: From basic research to clinical practice. World J Gastroenterol 17: 2288-2301, 2011.

13 Trouillas P, Marsal P, Svobodová A, Vostálová J, Gazák R, Hrbác J, Sedmera P, Kren V, Lazzaroni R, Duroux JL and Walterová D: Mechanism of the antioxidant action of silybin and 2,3-dehydrosilybin flavonolignans: A joint experimental and theoretical study. J Phys Chem A 112: 1054-1063, 2008.

$14 \mathrm{Li}$ Volti G, Salomone S, Sorrenti V, Mangiameli A, Urso V, Siarkos I, Galvano F and Salamone F: Effect of silibinin on endothelial dysfunction and ADMA levels in obese diabetic mice. Cardiovasc Diabetol 10: 62, 2011.

15 Loguercio C, Andreone P, Brisc C, Brisc MC, Bugianesi E, Chiaramonte M, Cursaro C, Danila M, de Sio I, Floreani A, Freni MA, Grieco A, Groppo M, Lazzari R, Lobello S, Lorefice E, Margotti M, Miele L, Milani S, Okolicsanyi L, Palasciano G, Portincasa P, Saltarelli P, Smedile A, Somalvico F, Spadaro A, Sporea I, Sorrentino P, Vecchione R, Tuccillo C, Del Vecchio Blanco $\mathrm{C}$ and Federico A: Silybin combined with phosphatidylcholine and vitamin $\mathrm{E}$ in patients with non alcoholic fatty liver disease: A randomized controlled trial. Free Radic Biol Med 52: 1658-1665, 2012.

16 Stiuso P, Scognamiglio I, Murolo M, Ferranti P, De Simone C, Rizzo MR, Tuccillo C, Caraglia M, Loguercio C and Federico A: Serum oxidative stress markers and lipidomic profile to detect NASH patients responsive to an antioxidant treatment: A pilot study. Oxid Med Cell Longev 2014: 169216, 2014.

17 Melchionda N, Forlani G, Marchesini G, Baraldi L and Natale S: WHO and ADA criteria for the diagnosis of diabetes mellitus in relation to body mass index. Insulin sensitivity and secretion in resulting subcategories of glucose tolerance. Int J Obes Relat Metab Disord 26: 90-96, 2002.

18 Ohkawa H, Ohishi N and Yagi K: Assay for lipid peroxides in animal tissues by thiobarbituric acid reaction. Anal Biochem 95: 351-358, 1979.

19 Urso ML and Clarkson PM: Oxidative stress, exercise, and antioxidant supplementation. Toxicology 189: 41-54, 2003.

20 Conti V, Russomanno G, Corbi G, Guerra G, Grasso C, Filippelli W, Paribello V, Ferrara $\mathrm{N}$ and Filippelli A: Aerobic training workload affects human endothelial cells redox homeostasis. Med Sci Sports Exerc 45: 644-653, 2013.

21 Lonardo A, Ballestri S, Marchesini G, Angulo P and Loria P: Nonalcoholic fatty liver disease: A precursor of the metabolic syndrome. Dig Liver Dis 47: 181-190, 2015.

22 Alberti KG, Zimmet P, Shaw J and IDF Epidemiology task force consensus group: The metabolic syndrome--a new world wide definition. Lancet 366(9491): 1059-1062, 2005.

23 Sundstrom J, Riserus U, Byberg L, Zethelius B, Lithell H and Lind L: Clinical value of the metabolic syndrome for long term prediction of total and cardiovascular mortality: Prospective, population based cohort study. BMJ 332: 878-882, 2006.

24 Soderberg C, Stal P, Askling J, Glaumann H, Lindberg G, Marmur J and Hultcrantz R: Decreased survival of subjects with elevated liver function tests during a 28-year follow-up. Hepatology 51: 595-602, 2010.

25 Luo J, Xu L, Li J and Zhao S: Nonalcoholic fatty liver disease as a potential risk factor of cardiovascular disease. Eur J Gastroenterol Hepatol 27: 193-199, 2015.

26 Long MT, Wang N, Larson MG, Mitchell GF, Palmisano J, Vasan RS, Hoffmann U, Speliotes EK, Vita JA, Benjamin EJ, Fox CS and Hamburg NM: Nonalcoholic fatty liver disease and vascular function: Cross-sectional analysis in the Framingham heart study. Arterioscler Thromb Vasc Biol 35: 1284-1291, 2015.

27 Dehmlow C, Erhard J and de Groot H: Inhibition of Kupffer cell functions as an explanation for the hepatoprotective properties of silibinin. Hepatology 23: 749-754, 1996. 
28 Comoglio A, Tomasi A, Malandrino S, Poli G and Albano E: Scavenging effect of silipide, a new silybin-phospholipid complex, on ethanol-derived free radicals. Biochem Pharmacol 50: 1313-1316, 1995.

29 Carini R, Comoglio A, Albano E and Poli G: Lipid peroxidation and irreversible damage in the rat hepatocyte model. Protection by the silybin-phospholipid complex IdB 1016. Biochem Pharmacol 43: 2111-2115, 1992.

30 Federico A, Morgillo F, Tuccillo C, Ciardiello F and Loguercio $\mathrm{C}$ : Chronic inflammation and oxidative stress in human carcinogenesis. Int J Cancer 121: 2381-2386, 2007.

31 Yoo HG, Jung SN, Hwang YS, Park JS, Kim MH, Jeong M, Ahn SJ, Ahn BW, Shin BA, Park RK and Jung YD: Involvement of NF-kappaB and caspases in silibinin-induced apoptosis of endothelial cells. Int J Mol Med 13: 81-86, 2004.

32 Trappoliere M, Caligiuri A, Schmid M, Bertolani C, Failli P, Vizzutti F, Novo E, di Manzano C, Marra F, Loguercio C and Pinzani M: Silybin, a component of sylimarin, exerts antiinflammatory and anti-fibrogenic effects on human hepatic stellate cells. J Hepatol 50: 1102-1111, 2009.
33 Isono M, Soda M, Inoue A, Akiyoshi $\mathrm{H}$ and Sato K: Reverse transformation of hepatic myofibroblast-like cells by TGFbeta1/LAP. Biochem Biophys Res Commun 311: 959-965, 2003.

34 Dong Y, Qu Y, Xu M, Wang X and Lu L: Catalase ameliorates hepatic fibrosis by inhibition of hepatic stellate cells activation. Front Biosci 19: 535-541, 2014.

35 Hernández-Ortega LD, Alcántar-Díaz BE, Ruiz-Corro LA, Sandoval-Rodriguez A, Bueno-Topete M, Armendariz-Borunda $\mathrm{J}$ and Salazar-Montes AM: Quercetin improves hepatic fibrosis reducing hepatic stellate cells and regulating pro-fibrogenic/antifibrogenic molecules balance. J Gastroenterol Hepatol 27: 1865$1872,2012$.
Received April 28, 2017

Revised May 13, 2017

Accepted May 15, 2017 